\title{
Perfil da proteção ambiental conferido ao oeste paranaense: Do Parque Nacional de Sete Quedas ao Parque Nacional de Ilha Grande
}

\author{
Environmental protection profile from Paraná's west: From Guaíra Falls to Illha Grande National \\ Park
}

\author{
Perfil de protección ambiental otorgado a la región del Paraná occidental: Desde el Parque \\ Nacional de Las Siete Cataratas al Parque Nacional de Ilha Grande
}

Recebido: 15/05/2021 | Revisado: 19/05/2021 | Aceito: 21/05/2021 | Publicado: 07/06/2021

\author{
Fernando Augusto Montai y Lopes \\ ORCID: https://orcid.org/0000-0003-1887-2141 \\ Instituto Federal de Educação, Ciência e Tecnologia do Paraná, Brasil \\ E-mail: fylopes@gmail.com \\ Máriam Trierveiler Pereira \\ ORCID: https://orcid.org/0000-0003-0782-6967 \\ Instituto Federal de Educação, Ciência e Tecnologia do Paraná, Brasil \\ E-mail: mariam.mestradoifpr@gmail.com \\ Samuel Ronobo Soares \\ ORCID: https://orcid.org/0000-0002-2027-9374 \\ Instituto Federal de Educação, Ciência e Tecnologia do Paraná, Brasil \\ E-mail: samuel.soares@ifpr.edu.br
}

\begin{abstract}
Resumo
O Parque Nacional (PARNA) de Ilha Grande foi criado em 1997, pelo Decreto federal de 30 de setembro de 1997, encampando um formato de preservação ambiental do tipo proteção integral, no qual a unidade de conservação exclui de seus limites territoriais a presença humana e direciona sua utilização única e exclusivamente para fins de pesquisas científicas, desenvolvimento de atividades de educação e interpretação ambiental, de recreação em contato com a natureza e de turismo ecológico. O presente estudo tem por objetivo analisar ao longo da história os diversos formatos de proteção ambiental conferidos à região do oeste paranaense, realizando um paralelo com as normas editadas no ordenamento jurídico brasileiro e os perfis dos pensamentos preservacionista, conservacionista e etnoconservacionista. Para tanto, este estudo utilizou-se do método de revisão bibliográfica e pesquisa de documentos e legislação nacional para traçar os diversos modelos de conservação implementados na região. No entanto, constatase que a proteção ambiental atribuída à região antes da criação do PARNA de Ilha Grande assumiu em determinados momentos um viés extremamente conservacionista e por vezes o Poder Público implementou políticas públicas em que os recursos naturais eram encarados apenas sob o enfoque de um desenvolvimento predatório. Após a instituição da atual unidade de conservação em outubro de 1997, as atuações ambientais pautaram-se pelo pensamento preservacionista e não geraram efetiva proteção ambiental.
\end{abstract}

Palavras-chave: Conservacionismo; Etnoconservação; Preservacionismo; Sustentabilidade; Unidade de conservação.

\begin{abstract}
The Ilha Grande National Park (PARNA - Parque Nacional da Ilha Grande) was created in 1997, by the Federal Decree of September 30, 1997, adopting an environmental preservation format, the type of integral protection, in which a conservation unit excludes from its territorial limits the human presence and directs its use solely and exclusively for the purposes of scientific research, development of educational activities and environmental interpretation, recreation in contact with nature and ecological tourism. The present study aims to analyze throughout history the different formats of environmental protection conferred to the region of the extreme West of Paraná, drawing a parallel with the norms published in the Brazilian legal system and the profiles of the preservationist, conservationist and ethnoconservationist thoughts. To this end, this study used the method of bibliographic review and searching of documents and national legislation to outline the various conservation models implemented in the region. However, it appears that the environmental protection attributed to the region before the creation of PARNA in Ilha Grande assumed at certain times an extremely conservationist bias and sometimes the government implemented public policies in which natural resources were viewed only under the focus of predatory development. After the establishment of the current conservation unit in October 1997, environmental actions were guided by preservationist thinking and did not generate effective environmental protection.
\end{abstract}

Keywords: Conservationism; Ethnoconservation; Preservationism; Sustainability; Conservation unit. 


\begin{abstract}
Resumen
El Parque Nacional Ilha Grande (PARNA) fue creado en 1997, mediante Decreto Federal del 30 de septiembre de 1997, adoptando un formato de preservación ambiental del tipo de protección integral, en el cual la unidad de conservación excluye de sus límites territoriales la presencia humana y dirige su uso única y exclusivamente con fines de investigación científica, desarrollo de actividades educativas e interpretación ambiental, recreación en contacto con la naturaleza y turismo ecológico. El presente estudio tiene como objetivo analizar a lo largo de la historia los diferentes formatos de protección ambiental conferidos a la región del Paraná occidental, haciendo un paralelo con las normas publicadas en el ordenamiento jurídico brasileño y los perfiles del pensamiento preservacionista, conservacionista y etnoconservacionista. Para ello, este estudio utilizó el método de revisión bibliográfica y búsqueda de documentos y legislación nacional para delinear los distintos modelos de conservación implementados en la región. Sin embargo, parece que la protección ambiental otorgada a la región antes de la creación del PARNA en Ilha Grande asumió en ciertos momentos un sesgo extremadamente conservacionista y en ocasiones el Poder Público implementó políticas públicas en las que los recursos naturales eran vistos solo bajo el enfoque del desarrollo depredador. Luego del establecimiento de la actual unidad de conservación en octubre de 1997, las acciones ambientales fueron guiadas por el pensamiento preservacionista y no generaron una protección ambiental efectiva.
\end{abstract}

Palabras clave: Conservación; Etnoconservación; Preservación; Sustentabilidad; Unidad de conservación.

\title{
1. Introdução
}

O Parque Nacional de Ilha Grande - PARNA de Ilha Grande, espaço especialmente protegido, possui uma área de aproximadamente de 78 mil hectares de extensão e grande parte do seu limite territorial localiza-se no oeste do Estado do Paraná (Instituto Chico Mendes de Conservação e Biodiversidade [ICMBio], 2020). Segundo a legislação de regência, o parque nacional se caracteriza como unidade de conservação do tipo proteção integral, na qual somente é permitida a realização de atividades de pesquisas científicas, educação e interpretação ambiental, recreação e de turismo ecológico (Lei n. 9985, 2000).

Entretanto, a referida unidade tem sido objeto de desmatamentos e queimadas de grandes proporções, o que afeta diretamente a biodiversidade local e a própria existência do PARNA de Ilha Grande. No ano de 2019, 47 mil hectares do espaço de preservação foram consumidos por um único incêndio que durou onze dias, representando uma degradação de $62 \%$ da extensão total da área legalmente protegida (Noroeste, 2019).

Pretendeu-se com o presente estudo analisar, do ponto de vista da sustentabilidade, as diversas formas de proteção legal ambiental e a implementação de políticas públicas em parte do oeste do Estado do Paraná ao longo do tempo, bem como os reflexos destas nos impactos ambientais e sociais na região.

Deve ser ponderado que a sustentabilidade envolve não apenas aspectos econômicos e de proteção ambiental, mas também se insere neste conceito a equidade e bem-estar social (Brundtland, 1987; Boff, 2014).

Ressalta-se, ainda, que o Brasil aderiu aos Objetivos de Desenvolvimento Sustentável - ODS propostos em 2015 pela Organização das Nações Unidas (ONU), que são orientações globais para o desenvolvimento de políticas públicas e de atividades de cooperação internacional para os próximos 15 anos. Neste contexto, esse trabalho se relaciona com os ODS 10 (redução das desigualdades), 13 (ação contra a mudança global do clima), 15 (vida terrestre) e 16 (paz, justiça e instituições eficazes). Conforme determina a Organização das Nações Unidas, a proteção legal e as políticas públicas ambientais devem proteger, recuperar e promover o uso sustentável dos ecossistemas terrestres, consubstanciando diretamente em medidas efetivas para o atingimento dos ODS (Organização das Nações Unidas [ONU], 2015).

Por fim, ressalta-se que a problemática proposta para o estudo exige uma interpretação de fatos e normativas brasileiras sob o ponto de vista das concepções conservacionistas, preservacionista e etnoconservacionista, que influenciaram a edição da legislação ambiental no Brasil, bem como a proteção ambiental no oeste paranaense.

\section{Metodologia}

Trata-se de trabalho de revisão bibliográfica, apreciação documental de diversas normas ambientais do ordenamento 
jurídico brasileiro, bem como a análise global de fatos e eventos relacionados a proteção ambiental direcionada ao oeste paranaense, sob um aspecto qualitativo, considerando a totalidade dos fenômenos e não apenas os dados ou aspectos isolados (Ludke \& André, 2013).

Para o desenvolvimento da revisão bibliográfica, utilizou-se da literatura já publicada sobre o tema, tais como os autores Antônio Carlos Diegues, Ignacy Sachs e estudiosos ligados ao Núcleo de Pesquisas em Limnologia, Ictiologia e Aquicultura da Universidade Estadual de Maringá (NUPELIA UEM) no formato de artigos científicos, livros, dissertações de mestrado e teses de doutorado. Os artigos científicos foram extraídos das plataformas Scielo e Google Acadêmico, além de revistas especializadas dos ramos do Direito, Geografia, História e Antropologia, publicados até o ano de 2020.

Além disso, com o objetivo de buscar fundamentos teóricos, analisou-se eventos históricos relacionados ao Brasil, bem como à região do oeste do Estado do Paraná. Para tanto, utilizou-se do método dialético, que permite o conhecimento de um determinado fenômeno ou objeto mediante o estudo de todos os seus aspectos, suas relações e conexões, sem tratar o conhecimento como algo rígido, já que tudo no mundo está sempre em constante mudança (Prodanov \& Freitas, 2013).

O estudo foi estruturado com base em um marco temporal, qual seja: a criação do PARNA de Ilha Grande em outubro de 1997. Assim, a análise foi dividida em duas sessões, sendo uma anterior a 1997 e outra após a criação da unidade de proteção em referência.

\section{Resultados e Discussão}

\subsection{Proteção ambiental conferida à região do oeste paranaense antes de outubro de 1997}

A criação do Parque de Yellowstone nos Estados Unidos da América - EUA em 1872 deu visibilidade a duas correntes de pensamento que influenciaram a criação de legislações e políticas públicas dirigidas à proteção de espaços naturais: o preservacionismo e o conservacionismo (Silva, Santos, Silva, \& Teixeira 2017).

Os ideais preservacionistas, encabeçados por John Muir, defendiam a necessidade de integral proteção e preservação do meio ambiente contra os avanços da degradação intentada por intervenções humanas, defendendo, ainda, igualdade de direitos entre homens e a natureza e erigindo essa à sujeito de direitos. Já o pensamento conservacionista, que tem como grande expoente Gifford Pinchot, encampou a ideia de que a proteção especial a determinados espaços deveria ocorrer a partir do uso equilibrado pelo homem dos recursos naturais disponíveis, o que embasaria posteriormente o conceito de desenvolvimento sustentável (Diegues, 2008).

No caso específico da instituição do Parque de Yellowstone prevaleceu o formato preconizado pelo preservacionismo, modelo também conhecido como conservação de fortaleza - fortress conservation - (Igoe, 2004). Essa concepção preservacionista reverberou no Brasil, sendo externado pelo engenheiro e político André Pinto Rebouças o interesse na criação do Parque Nacional de Setes Quedas na Província do Paraná, em artigo denominado "Parque Nacional" publicado em 1876 (Urban, 1998).

Deve ser ponderado que o Estado do Paraná foi a primeira unidade federativa a editar um Código Florestal no Brasil por meio da Lei n. 706/1907, que trouxe o embrião das atuais áreas de preservação permanente e reserva legal, ao regulamentar as florestas protetoras de nascentes e cursos d'água, montanhas e encostas (Roriz \& Fearnside, 2013). No entanto, tratava-se de uma legislação de caráter utilitarista e de quase nenhuma aplicação na prática (Carvalho \& Laverdi, 2015).

A proposta preconizada por André Pinto Rebouças somente se efetivou depois de 85 anos, com a criação do Parque Nacional de Sete Quedas pelo Decreto Federal n. 50.665/1961, que inclui em seus limites as ilhas e ilhotas dos Estados do Paraná e Mato Grosso, entre elas a Ilha Grande e a dos Bandeirantes, que hoje compõem o PARNA de Ilha Grande (Decreto n. $50.665,1961)$.

À época da instituição do Parque de Sete Quedas, encontrava-se vigente no Brasil o Código Florestal de 1934, 
instituído pelo Decreto n. 23.793, de 23 de janeiro de 1934, editado pelo então Presidente Getúlio Vargas. De acordo com esse diploma legal, os parques constituíam monumentos públicos naturais, que perpetuavam em sua composição florística primitiva trechos de paz, sendo proibido o exercício de qualquer espécie de atividade contra sua flora e a fauna.

Posteriormente, durante o Governo Militar, foi editado um novo Código Florestal pela Lei n. 4.771/1965, regulada pelo Decreto n. 84.017/1979, estabelecendo aos parques nacionais o único escopo de resguardar atributos excepcionais da natureza, conciliando esta proteção integral com a utilização para objetivos educacionais, recreativos e científicos.

De acordo com Laureano e Magalhães (2011), a legislação ambiental de 1934 visava proteger coberturas vegetais contra a dilapidação do patrimônio florestal do país. Já o Código de 1965 consolidava uma política intervencionista do Estado sobre a propriedade imóvel na medida em que as florestas existentes no território nacional e as demais formas de vegetação eram consideradas bens de interesse comum a todos os habitantes do País.

Durante o governo militar (1964-1985), adotou-se uma política pública desenvolvimentista, na qual o Estado implementou diversas políticas públicas direcionadas à criação de infraestruturas e de um aparato institucional aos moldes de uma modernização conservadora (Andrade \& Iadanza, 2016), editando-se consecutivos Planos Nacionais de Desenvolvimento (Leuzinger, 2012).

Assim, impulsionados pelo ideal desenvolvimentista e utilitarista, o Brasil firmou, no início da década de 1970, tratado internacional com a República do Paraguai com o escopo de realizar o aproveitamento hidrelétrico dos recursos hídricos do Rio Paraná, desde e inclusive o Salto Grande de Sete Quedas até a Foz do Rio Iguaçu, formando as bases para criação da Usina Hidrelétrica Itaipu Binacional (Decreto n. 72.707, 1973). Diante dessa conjectura internacional, o Parque Nacional de Sete Quedas foi extinto com a edição do Decreto n 8.071/1981, tendo em vista que a instalação da barragem da Hidrelétrica de Itaipu acarretaria a inundação e cobertura do acidente natural de Sete Quedas.

No início da década de 1980, o Governo Federal divulgou na imprensa o interesse na construção da Hidrelétrica de Ilha Grande (Godoy, 2002), inclusive editando o Decreto n. 90.749/84, que declarou de utilidade pública, para fins de desapropriação, as áreas de terra de propriedades particulares necessárias à formação da primeira etapa do reservatório da usina nos municípios de Altônia, Francisco Alves, Guaíra, Iporã, Palotina, Pérola, Terra Roxa e Umuarama no Estado do Paraná, e nos Municípios de Eldorado, Iguatemi, Mundo Novo e Naviraí no Estado de Mato Grosso do Sul (Decreto n. 90.749, 1984).

Como base nesses fatos, observou-se uma diminuição da proteção ambiental na região e, paralelamente, houve uma intensificação do projeto de colonização pelo Instituto Nacional de Colonização e Reforma Agrária (INCRA) nos municípios de Mundo Novo, Iguatemi e Sete Quedas, loteando-se 250 ilhas do Rio Paraná por intermédio da entrega de títulos de posse a aproximadamente 995 posseiros em 1979 (Rosa, 1996). Essa titulação objetivava garantir aos indivíduos, que tinham posse precária de terras localizadas nas ilhas, indenizações pelas áreas que seriam alagadas com a construção da Hidrelétrica de Ilha Grande (Motta \& Campos, 2001).

No entanto, ao final da década de 1980 e início de 1990, identificou-se alguns movimentos para proteção ambiental no oeste paranaense, o que resultou na edição de leis municipais em São Jorge do Patrocínio, Altônia e Alto Paraíso, criando em seus limites territoriais três Áreas de Proteção Ambiental (APA) para resguardo do ecossistema na Ilha Grande, seus arquipélagos e áreas compreendidas às margens ocidentais do Rio Paraná, restringindo atividades agropecuárias e extrativistas (Godoy, 2002).

Esse movimento de estabelecimento de APAs municipais também foi incentivado pela edição da Lei Complementar Estadual n. 59/1991, que de forma inovadora no Brasil direcionou uma parcela maior de repasse do Imposto sobre Operações relativas à Circulação de Mercadorias e sobre Prestações de Serviços de Transporte Interestadual e Intermunicipal e de Comunicação - ICMS paranaense aos municípios que abrigavam unidades de conservação (Decreto n. 4.464, 1991).

No final de 1994, o Estado do Paraná criou a Estação Ecológica de Ilha Grande, localizada nos municípios de 
Antônia, São Jorge do Patrocínio e Vila Alta com área total de 28.367,3322 ha (Lei complementar n. 59, 1994). A referida unidade de conservação foi instituída com base na Lei n. 6.902/81, a qual se estipulava como objetivo de proteção assegurar exemplar representativo de ecossistemas brasileiros, destinando-os à realização de pesquisas básicas e aplicadas de ecologia, à proteção do ambiente natural e ao desenvolvimento da educação conservacionista.

Somente em 1997, o Governo Federal instituiu o Parque Nacional de Ilha Grande como medida compensatória decorrente da obra pública de complexo de pontes "Luiz Eduardo Magalhães", que liga o Estado do Paraná e o de Mato Grosso do Sul pelos municípios de Icaraíma-PR e Naviraí-MS (ICMBio, 2002).

Identifica-se, portanto, que o formato da proteção ambiental conferido ao oeste paranaense em data anterior a outubro de 1997 assumiu um perfil ora preservacionista, ora utilitarista, oscilando entre iniciativas de criação de áreas para pura proteção do meio ambiente, instituição de barragens de represamento para hidrelétricas e políticas públicas de colonização da região com a concessão de títulos de propriedades privadas.

\subsection{Proteção ambiental conferida à região do oeste paranaense após outubro de 1997}

O PARNA da Ilha Grande foi instituído pelo Decreto sem número de 30 de setembro de 1997, abrangendo as Ilhas Grande, Peruzzi, do Pavão e Bandeirantes e todas as demais ilhas e ilhotas situadas desde o reservatório de Itaipu e a foz do Rio Piquiri até a foz dos Rios Amambai e Ivaí, as áreas de várzea e planícies de inundação, situadas às margens do Rio Paraná, as águas lacustres e lagunares e seu entorno e o Paredão das Araras.

Curiosamente, a normativa em referência excluiu laconicamente de seus limites territoriais as águas fluviais destinadas à navegação, o que gera divergência de interpretação quanto ao fato do Rio Paraná compor ou não o PARNA de Ilha Grande. No entanto, a posição das lideranças políticas e ambientais regionais, que participaram da elaboração da proposta de criação da unidade, é que esse trecho do Rio Paraná foi excluído dos limites do parque (ICMBio, 2002).

De acordo com o art. $5^{\circ}$ do decreto de instituição, todas as propriedades privadas localizadas dentro dos limites na nova unidade de conservação são declaradas de utilidade pública, devendo as mesmas serem desapropriadas. Essa determinação vai ao encontro do perfil da unidade de conservação instituída pelo Código Florestal vigente à época da criação (Lei n. 4.771/1965), o qual impõe aos parques nacionais o único e específico escopo de resguardar atributos excepcionais da natureza, direcionando a proteção integral para utilização educacional, recreativa e científica.

Os contornos legais atribuídos ao PARNA de Ilha Grande demonstram um viés puramente conservacionista, dissociando-se de aspectos sociais locais e não considera as especiais relações que populações tradicionais possuem com o meio ambiente que se pretende proteger. Como ensina Diegues (2000), os parques nacionais no Brasil são áreas geográficas extensas e delimitadas, dotadas de atributos naturais excepcionais e voltados para a criação de atrações, como recreação, turismo e educação ambiental, ou seja, usos que são direcionados às populações externas à área, desconsiderando populações indígenas, de pescadores, ribeirinhas e de coletores que nela habitam.

No entanto, deve ser ponderado que no momento da instituição do PARNA de Ilha Grande já se encontravam vigentes no ordenamento jurídico a Lei n. 6.938/81, que instituiu a Política Nacional de Meio Ambiente, bem como a Constituição Federal de 1988, que se afastam de uma concepção puramente preservacionista e considera o meio ambiente como um direito fundamental do povo brasileiro, indicando o abandono de uma visão meramente utilitarista de preservação e início de uma concepção de conservação da biodiversidade e da sociodiversidade. Essa nova forma de compreensão das unidades de conservação foi acentuada com a Conferência Mundial do Meio Ambiente realizada no Rio de Janeiro 1992 (Garrote, Dambrowski, Dos Santos, \& Amaro, 2017).

Em 2000, foi editada nova legislação sobre espaços especialmente protegidos, criando-se o Sistema Nacional de Unidade de Conservação - SNUC (Lei n. 9.985, 2000), que teve por base o disposto no art. 225, $\S^{\circ}$, III, da Constituição 
Federal de 1988). A legislação em comento continuou caracterizando os parques nacionais como unidades do tipo proteção integral, mantendo como objetivo básico a preservação da natureza e admitindo apenas o uso indireto de seus recursos naturais.

O SNUC delineou a existência de duas espécies de unidades de conservação, tendo ainda por base os modelos propostos pelos movimentos preservacionista e conservacionista norte-americanos do século XIX, quais sejam: Unidades de Proteção Integral e Unidades de Uso Sustentável (Xavier, 2018).

No entanto, deve ser ponderado que em razão de movimentos ambientalistas impulsionados por comunidades tradicionais amazônicas, o SNUC absorveu ideias do etnoconservacionismo (socioconservacinismo), no qual se propõe a estabelecimento de áreas protegidas com a presença humana em seus limites, apresentando enfoque tanto na proteção ambiental, bem como no aspecto social das comunidades tradicionais, como é o caso de reservas de uso sustentável e reservas extrativistas (Fernandez, 2016).

O SNUC, ao estabelecer os regramentos dos parques nacionais, continuou utilizando-se de parâmetros do sistema norte-americano de proteção ambiental, que é baseado na noção de natureza intocada, considerando que áreas naturais deveriam ser protegidas contra as atividades humanas, com exceção daquelas relacionadas ao turismo, medidas educativas e pesquisas científicas (Calegare, Higuchi, \& Bruno, 2014).

O formato de proteção integral escolhido para a criação do PARNA de Ilha Grande não permite a presença humana em seus limites, o que gerou a expulsão daqueles que habitavam os limites territoriais da unidade de conservação. De acordo com relatório circunstanciado de identificação e delimitação de terra indígena elaborado pela Fundação Nacional do Índio FUNAI no processo administrativo n. 08620.010333/2015-46, a instituição do parque nacional gerou a expulsão de, aproximadamente, oito aldeamentos indígenas que residiam na unidade de conservação. Ressalta-se, ainda, que de acordo com o citado relatório, há ainda dentro do PARNA uma família indígena, bem como há a indicação de que o parque é utilizado pelos demais Avá-Guaranis da região (Fundação Nacional do Índio [FUNAI], 2018).

No mesmo sentido, houve a expulsão dos limites territoriais de comunidades de ilhéus, que lá residiam de forma precária ou mediante a titulação concedida pelo INCRA 1979. Essa população tradicional utilizava as ilhas do Rio Paraná principalmente para extração de Faffia (Pfaffia glomerata), conhecida como ginseng-brasileiro (Godoy, 2002).

No ano de 2011, a Colônia de Pescadores Profissionais de Mundo Novo - MS ajuizou a ação n. 500607924.2011.4.04.7000 perante a Justiça Federal do Tribunal Regional Federal da $4^{a}$ Região (TRF4), buscando a declaração de caducidade do ato de criação do PARNA de Ilha Grande, sob a justificativa de que o Poder Público não teria realizado a devida indenização das propriedades que foram desapropriadas pelo decreto federal sem número de 30 de setembro 1997 (Tribunal Regional Federal da $4^{a}$ Região [TRF4], 2020).

No entanto, o TRF4 afastou a tese de caducidade, mantendo hígido o ato legal de sua criação, sob a justificativa de que somente a lei poderia desafetar ou alterar o status de uma unidade de conservação, nos termos do que preconiza o art. $22, \S$ $7^{\circ}$ da Lei 9.985/00 e o art. 225, § 1. ${ }^{\circ}$, III, da Constituição Federal.

Após a criação do PARNA de Ilha Grande, a principal preocupação do Poder Público centrou-se na manutenção da concepção preservacionista de paraíso natural intocado, aos moldes da conservação de fortaleza, pois optou pela instituição de unidade de conservação do tipo proteção integral.

No entanto, o modelo atualmente adotado não se apresentou efetivo contra a principal ameaça ao meio ambiente na região, que são as constantes ocorrências de incêndios. Entre os anos de 1999 a 2003, registrou-se cinquenta e dois incêndios no PARNA de Ilha Grande, com uma média de 10,4 ocorrências por ano. Esses eventos degradantes ao meio ambiente normalmente são frutos de causas criminosas, origem desconhecida ou, ainda, relacionadas às atividades de agricultura (Koproski, Batista, \& Soares, 2004).

De acordo com o ICMBio (2015), entre os anos de 2000 a 2015, 53\% dos incêndios causados ao PARNA de Ilha 
Grande são de origem antrópicas, 15\% por causas naturais (raios) e 32\% por causas não conhecidas. Além disso, Fragal (2018) afirma que a frequência de queimadas aumentou de cinco a seis vezes na parte central do PARNA de Ilha Grande após a sua criação, bem como se constatou que não houve redução de queimadas em comparação ao período anterior a sua instituição.

Para localidades em que a problemática de proteção ao meio ambiente se entrelaça com questões sociais, econômicas, culturais e políticas, exige-se uma atuação dos diversos gestores ambientais sob o viés da etnoconservação, que se mostra eficaz justamente por se posicionar de forma interdisciplinar, considerando a vasta amplitude de conhecimentos e iterações firmadas entre os seres humanos e o ambiente que os cerca (Barbosa \& Aguiar, 2018).

Portanto, por um lado, o preservacionismo e o conservacionismo são linhas de pensamento focadas na estrita proteção da natureza, buscando o isolamento de áreas protegidas. Por outro lado, o socioambientalismo ou etnoconservação caracterizase pela compatibilização da presença humana em áreas especialmente protegidas, reconhecendo a importância social e cultural de determinados grupos locais e visa a promoção do desenvolvimento sustentável com respeito ao ecossistema (Furriela, 2004).

O pensamento etnoconservacionista prima pela participação da sociedade na gestão ambiental de unidades de conservação, que se apresenta como uma articulação entre meio ambiente e democracia (Santilli, 2004). Ressalta-se que a legislação que instituiu o SNUC também indica essa possibilidade de articulação em seu art. $4^{\circ}$, XIII, ao instituir como objetivo do sistema a proteção de recursos naturais necessários à subsistência de populações tradicionais, respeitando e valorizando seu conhecimento e sua cultura e promovendo-as social e economicamente (Silva \& Rocha, 2018).

A implementação de políticas públicas etnoconservacionistas na região do oeste paranaense tem o potencial de gerar efetiva preservação ambiental. Há estudos recentes indicando essa maior proteção, tal como o elaborado pela University of British Columbia, que constatou um maior nível de preservação em terras administradas por indígenas em comparação a áreas meramente protegidas por lei, como parques e reservas de vida selvagem (Richard, Ryan, Joseph, Nicholas, \& Peter, 2019).

Reconhece-se a importância da criação de espaços especialmente protegidos, mas há a necessidade de implementação de estratégias políticas e de gestão por parte do Poder Público, comunidades locais, organizações governamentais e não governamentais e iniciativa privada, a fim de se atingir determinadas metas de ordenamento territorial para consolidação das funções sociais e ambientais relativas às unidades de conservação (Vallejo, 2002).

A defesa do meio ambiente local não pode se concretizar unicamente na criação de santuários invioláveis e desconectados da realidade local, pois sua instituição sem os meios necessários para uma proteção efetiva se apresenta como uma política pública autoderrotada (Sachs, 2009).

\section{Considerações Finais}

A região onde se localiza atualmente o PARNA de Ilha Grande recebeu ao longo dos tempos diversas proteções legais e implementação de políticas públicas ambientais para proteção do meio ambiente natural, encontrando-se manifestações públicas em favor da proteção que datam da época do Império brasileiro.

No entanto, a primeira proteção específica ocorreu com a criação do Parque Nacional de Sete Quedas em 1961, encampando-se o formato de proteção preservacionista, no qual o meio ambiente, objeto de proteção, não permite a presença humana em seus limites.

Mesmo com o transcorrer dos anos, as sucessivas proteções legais e políticas públicas aplicadas na região, bem como a que culminou no estabelecimento do PARNA de Ilha Grande em 1997, assumiram feição preservacionista. Atualmente, o perfil da unidade de conservação analisada, bem como sua gestão ainda estão intrinsecamente ligados aos conceitos de preservação de fortaleza e seus fins são direcionados apenas à pesquisa científica, atividades educacionais e de turismo.

O formato de preservação estabelecido proporcionou uma atuação do Poder Público focada na desocupação 
populacional dos limites territoriais do parque e não gerou efetiva proteção ambiental, pois não coibiu a principal causa de degradação ambiental, que são as constantes queimadas.

Diante deste cenário e com perspectivas de elaboração de novos trabalhos sobre o tema, questiona-se a necessidade de implementação de novo viés de gestão da área especialmente protegida, indicando-se a necessidade de uma política pública etnoconservacionista como alternativa para efetiva preservação do meio ambiente e promoção de comunidades tradicionais locais.

\section{Referências}

Andrade, M. P., \& Iadanza, E. E. S. (2016). Unidades de Conservação no Brasil: Algumas considerações e desafios. Revista de Exten são e Estudos Rurais, 5(1), 81-96. https://doi.org/10.36363/rever512016\%25p

Barbosa, J. A. A., \& Aguiar, J. O. (2018). Etnoconservação e história ambiental para um novo modelo conservacionista do século XXI. Novos Cadernos NAEA, 21(1), 243-255. http://dx.doi.org/10.5801/ncn.v21i1.3795

Boff, L. (2014). Sustentabilidade: o que é - o que não é: Vozes.

Brundtland, G. H. (1987). Relatório Brundtland. https://ambiente.files.wordpress.com/2011/03/brundtland-report-our-common-future.pdf

Calegare, M. G. A., Higuchi, M. I. G., \& Bruno, A. C. S. (2014). Povos e comunidades tradicionais: das áreas protegidas à visibilidade política de grupos sociais portadores de identidade étnica e coletiva. Ambiente \& Sociedade, 17(3), 115-134. https://doi.org/10.1590/S1414-753X2014000300008

Carvalho, A. I., \& Laverdi, R. (2015). Espécie e Florestas: A araucária nos discursos ambientais e na produção de sentidos para as florestas no Paraná. Fronteiras: Journal of Social, Techological and Environmental Science, 4(1), 224-248. https://doi.org/10.21664/2238-8869.2015v4i1.p224-248

Constituição da República Federativa do Brasil de 1998. (1998). Brasília. Recuperado em 25 julho, 2020, de http://www.planalto.gov.br/ccivil_03/constituicao/constituicao.htm

Decreto n. 50.665, de 30 de maio de 1961. (1961). Cria o Parque Nacional de Sete Quedas e dá outras providências. Brasília. https://www2.camara.leg.br/legin/fed/decret/1960-1969/decreto-50665-30-maio-1961-390248-publicacaooriginal-1-pe.html

Decreto n. 72.707, de 28 de agosto de 1973. (1973). Promulga o Tratado entre a República Federativa do Brasil e a República do Paraguai, para o Aproveitamento Hidrelétrico dos Recursos Hídricos do Rio Paraná, Pertencentes em Condomínio aos dois Países, desde e inclusive o Salto Grande de Sete Quedas ou Salto de Guaíra até a Foz do Rio Iguaçu, bem como as seis Notas trocadas entre os Ministros da Relações Exteriores dos dois países. Brasília. http://www.planalto.gov.br/ccivil_03/decreto/Antigos/D72707.htm

Decreto n. 84.017, de 21 de setembro de 1979. (1979). Aprova o Regulamento dos Parques Nacionais Brasileiros. Brasília. http://www.planalto.gov.br/ccivil_03/Atos/decretos/1979/D84017.html

Decreto n. 86.071, de 4 de junho de 1981. (1981). Extingue o Parque Nacional de Sete Quedas, criado pelo Decreto n 50665, de 30 de maio de 1961, e dá outras providências. Brasília. https:/www2.camara.leg.br/legin/fed/decret/1980-1987/decreto-86071-4-junho-1981-435549-publicacaooriginal-1-pe.html

Decreto n. 90.749, de 21 de dezembro de 1984. (1984). Declara de utilidade pública, para fins de desapropriação, áreas de terra necessárias à formação da $1^{\text {a }}$ etapa do reservatório da usina hidrelétrica de Ilha Grande, da Centrais Elétricas do Sul do Brasil S.A.-ELETROSUL, nos Estados do Paraná e Mato Grosso do Sul. Brasília. https://www2.camara.leg.br/legin/fed/decret/1980-1987/decreto-90749-21-dezembro-1984-440991-norma-pe.html

Decreto n. 4.464 de 01 de outubro 1991. (1991). Dispõe sobre a repartição do ICMS, a que alude o art. $2^{\circ}$ da Lei 9.491 , de 21 de dezembro de 1990 , aos municípios com manciais de abastecimento e unidades de conservação. https://www.legislacao.pr.gov.br/legislacao/exibirAto.do?action=iniciarProcesso\&codAto=19751\&codItemAto=199503

Decreto de 30 de setembro de 1997. (1997). Cria o Parque Nacional de Ilha Grande, nos Estados do Paraná e Mato Grosso do Sul, e dá outras providências. Brasília. http://www.planalto.gov.br/ccivil_03/DNN/Anterior\%20a\%202000/1997/Dnn5785.htm

Diegues, A. C. S. 'A. (2000). Etnoconservação da natureza: enfoques alternativos. In Etnoconservação: novos rumos para a proteção da natureza nos trópicos (p. 1-46): HUCITEC/NUPAUB.

Diegues, A. C. S. 'A. (2008). O mito moderno da natureza intocada: HUCITEC/NUPAUB.

Fernandez, A. C. F. (2016). O sertão formal da política brasileira de conservação da natureza. Revista Brasileira de Ciência Política, 20, 165-204. https://dx.doi.org/10.1590/0103-335220162005

Fragal, E. H. (2018). Dinâmica de queimadas em áreas úmidas protegidas e relações com fatores ambientais e antrópicos: o Parque Nacional de Ilha Grande (PR-MS). Tese de doutorado, Universidade Estadual de Maringá, Maringá, PR, Brasil.

Fundação Nacional do Índio. (2018). Despacho n 2. Processo n. 08620.010333/2015-46. Resumo do relatório circunstanciado de identificação e delimitação da terra indígena Tekoha Guasu Guavirá. https://www.in.gov.br/materia/-/asset_publisher/Kujrw0TZC2Mb/content/id/45172171/do1-2018-10-15-despacho-n-2de-setembro-de-2018-45171952?fbclid=IwAR0sQLKxvtVxD8C0RPMh4OpbUYvmO4tF4zU9vG_i7indGpMHHAeeBoxcDOY

Furriela, R. B. (2004). O movimento ambientalista no Brasil: evolução histórica e o desafio do equilíbrio socioambiental. In: F. Ricardo. Terras indígenas e unidades de conservação da natureza: o desafio das sobreposições (p. 64-65). São Paulo: Instituto Socioambiental. 
Garrote M. S., Dambrowski V., Dos Santos G. F., \& Amaro J. G. (2017). Evolução Das Políticas Conservacionistas e a Criação de Unidades de Conservação no Vale do Itajaí-Sc. Holos, 01(34), 61-80. https://doi.org/10.15628/holos.2018.4428

Godoy, A. M. G. (2002). A População do Parque Nacional de Ilha Grande. Cadernos da Biodiversidade. Cadernos da Biodiversidade, 3(3), 30-42. Curitiba: DIBAP/IAP. http://www.iat.pr.gov.br/sites/agua-terra/arquivos_restritos/files/documento/2020-09/capa_cadernos_biodiversidade.pdf

Igoe, J. (2004). Fortress conservation: A social history of national parks. In: J. A. Young. Conservation and globalization: a study of National Parks and Indigenous Communities from East Africa to South Dakota (p. 69-102). Belmont: Wadsworth/Thompson Learning.

Instituto Chico Mendes de Conservação e Biodiversidade. Relato. https://www.icmbio.gov.br/portal/visitacao1/unidades-abertas-a-visitacao/4239-parna-ilhagrande

Instituto Chico Mendes de Conservação e Biodiversidade. (2008). Plano de Manejo para o Parque Nacional de Ilha Grande. https://www.icmbio.gov.br/portal/images/stories/docs-planos-de-manejo/parna_ilha_grande_pm.pdf

Instituto Chico Mendes de Conservação e Biodiversidade. (2015). Plano operativo de prevenção e combate aos incêndios florestais do Parque Nacional de Ilha Grande - PR/MS. http://www.icmbio.gov.br

Koproski, L. P., Batista, A. C., \& Soares, R. V. (2004). Ocorrências de incêndios florestais no Parque Nacional de Ilha Grande - BRASIL. Revista Floresta, 34(2), 193-197. http://dx.doi.org/10.5380/rf.v34i2.2395

Laureano, D. S., \& Magalhães J. L. Q. (2011). Código Florestal e catástrofes climáticas. EcoDebate. https://www.ecodebate.com.br/2011/02/16/codigoflorestal-e-catastrofes-climaticas-artigo-de-delze-dos-santos-laureano-e-jose-luiz-quadros-de-magalhaes/

Lei n. 4.771, de 15 de setembro de 1965. (1965). Institui o novo Código Florestal. Brasília. http://www.planalto.gov.br/ccivil_03/leis/14771.htm

Lei complementar n. 59, de 26 de dezembro de 1994. (1994). Criação da Estação Ecológica de Ilha Grande localizada nos municípios de Altônia, São Jorge no

Estado do Paraná. Curitiba. https://www.legislacao.pr.gov.br/legislacao/pesquisarAto.do?action=exibir\&codAto=20693\&indice=1\&totalRegistros=1\&dt=8.11.2020.17.5.22.959

Lei n. 9.985, de 18 de julho de 2000. (2000). Regulamenta o art. 225, § $1^{\circ}$, incisos I, II, III e VII da Constituição Federal, institui o Sistema Nacional de Unidades de Conservação da Natureza e dá outras providências. Brasília. http://www.planalto.gov.br/ccivil_03/leis/19985.htmLeuzinger, M. (2012). Breve panorama da legislação ambiental brasileira. In: M. O. Cases (Org.). Gestão de Unidades de Conservação: compartilhando uma experiência de capacitação (p. 57-72). $\quad$ Brasília: $\quad$ WWF/Brasil/Ipê $\quad-\quad$ Instituo $\quad$ de https://d3nehc6yl9qzo4.cloudfront.net/downloads/gestao_de_unidades_de_conservacao.pdf

Ludke, M., \& André, M. E. D. A. (2013). Pesquisas em educação: uma abordagem qualitativa: E.P.U.

Motta M. N. J., \& Campos, J. B. (2001). Antecedentes históricos de proteção ambiental às Ilhas e Várzeas do Rio Paraná. In: J. B. Campos (Org.). Parque Nacional de Ilha Grande: re-conquistas e desafios (p. 20-29). Maringá, PR: IAP.

Noroeste, R. P. C. (2019, agosto 22). Incêndio no Parque Nacional de Ilha Grande é controlado, diz ICMBio. G1. https://g1.globo.com/pr/nortenoroeste/noticia/2019/08/22/incendio-no-parque-nacional-de-ilha-grande-e-controlado-diz-icmbio.ghtml

Organização Das Nações Unidas. (2015). Agenda 2030. https://nacoesunidas.org/pos2015/agenda2030/

Prodanov, C. C., \& Freitas, E. C. F. (2013). Metodologia do trabalho científico: métodos e técnicas da pesquisa e do trabalho acadêmico. Novo Hamburgo, RJ: Feevale.

Richard S., Ryan R. G., Joseph R. B., Nicholas J. R., \& Peter A. (2019). Vertebrate biodiversity on indigenous-managed lands in Australia, Brazil, and Canada equals that in protected areas. Environmental Science \& Policy, 101, 1-6. https://doi.org/10.1016/j.envsci.2019.07.002

Rosa, M. C. (1996). Processo de ocupação e situação atual. In: A. E. A. M., Vazzoler, A. A., Agostinho, \& N. S. Hahn (Orgs.). A Planície de inundação do alto Rio Paraná. Aspectos físicos, biológicos e socioeconômicos (p. 371-394). Maringá, PR: EDUEM/NUPELIA.

Roriz, P. A. C., \& Fearnside, P. M. (2013). Áreas de preservação permanente e reserva legal: Da criação à descaracterização. Anais do XVII Encontro Latino Americano de Iniciação Científica, XIII, Encontro Latino Americano de Pós-Graduação e III Encontro de Iniciação à Docência da Universidade da Paraíba. São José dos Campos, SP, Brasil. http://philip.inpa.gov.br/publ_restritas/2013/Roriz\%20\&\%20Fearnside_C\%C3\%B3digo_Florestal_RE_0969_0776_01.pdf.

Sachs, I. (2009). Caminhos para o desenvolvimento sustentável: Garamond.

Santilli, J. (2004). Povos indígenas, quilombolas e populações tradicionais: a construção de novas categorias jurídicas. In: F. Ricardo. Terras indígenas e unidades de conservação da natureza: o desafio das sobreposições (p. 42-49). São Paulo: Instituto Socioambiental.

Silva, M. M., Santos, I. F, Silva, F. R. C., \& Teixeira, C. P. (2017). Unidades de Conservação e Comunidades Locais: Gestão de Conflitos e Instrumentos de Participação. Estudo \& Debate, 24(3), 208-218. http://dx.doi.org/10.22410/issn.1983-036X.v24i3a2017.1397

Silva, T. O. Da., \& Rocha, C. G. S. (2018). "My boat I do not leave": right of land use in the Serra do Pardo National Park by the beiradeiros, Pará, Brasil. Research, Society and Development, 7(10), 1-20. https://doi.org/10.17648/rsd-v7i10.426

Tribunal Regional Federal da $4^{a}$ Região. (2020). https://www.trf4.jus.br/trf4/

Urban, T. (1998). Saudade do Matão: relembrando a história da conservação da natureza no Brasil. Curitiba, PR: UFPR/Fundação O Boticário de Proteção à Natureza/Fundação MacArthur. 
Research, Society and Development, v. 10, n. 6, e47010616112, 2021

(CC BY 4.0) | ISSN 2525-3409 | DOI: http://dx.doi.org/10.33448/rsd-v10i6.16112

Vallejo, L. R. (2002). Unidade de Conservação: Uma Discussão Teórica á Luz dos Conceitos de Território e Políticas Públicas. GEOgraphia, 4(8), 57-78. https://doi.org/10.22409/GEOgraphia2002.v4i8.a13433

Xavier, M. T. (2018). Unidades de Conservação: Reflexões sobre a falácia do desenvolvimento sustentável. O Social em Questão, 40(21), 161-184, 2018. http://osocialemquestao.ser.puc-rio.br/media/OSQ_40_art_7_Xavier.pdf 